\title{
Efeito do Nível de Trigo na Dieta, do Percentual de Grãos Germinados e da Forma Física da Ração sobre o Desempenho de Frangos de Corte
}

\author{
Paulo Antonio Rabenschlag de Brum 1,2, Gustavo Júlio Mello Monteiro de Lima ${ }^{1,2}$, Helenice \\ Mazzuco ${ }^{1}$, Flávio Bello Fialho', Eliana Maria Guariente ${ }^{3}$, Eduardo Spillari Viola ${ }^{4}$
}

RESUMO - O objetivo deste trabalho foi determinar o melhor nível de substituição do milho por trigo, com 0 e $9 \%$ de grãos germinados (GG) em rações para frangos de corte. Rações fareladas (RF) na fase inicial (1 a 21 dias), trituradas (RT) na fase de crescimento (21 a 35 dias) e peletizadas (RP) na fase final ( 35 a 42 dias) foram usadas. Foi usado delineamento experimental em blocos casualizados, com cinco tratamentos e 12 repetições de 26 aves, na fase inicial, e 10 tratamentos e seis repetições de 26 aves, nas fases de crescimento e final. Os tratamentos foram: T1 - dieta à base de milho e farelo de soja (DMFS); T2 e T4 - substituição de 50\% do milho da dieta T1 por trigo com 0 e $9 \%$ GG, respectivamente; e T3 e T5 - substituição de $100 \%$ do milho por trigo com 0 e $9 \%$ GG, respectivamente. O uso de RT de 21 a 35 dias e RP de 35 a 42 dias de idade aumentou o peso corporal (PC), ganho de peso (GP) e consumo de ração (CR). Contudo, a conversão alimentar somente foi melhor com a RT de 21 a 35 dias. O trigo com até $9,0 \%$ GG poderia substituir totalmente o milho em dietas de frangos de corte, quando comparadas à DMFS. Nas dietas à base de trigo e farelo de soja, o trigo com $0 \%$ GG determinou maiores PC, GP e CR que o trigo com $9 \%$ GG.

Palavras-chave: desempenho, forma de ração, frango de corte, ingredientes, trigo

\section{Effect of the Wheat Level in the Diet, of the Percentage of Germinated Grains and Physical Form of the Feed on the Performance of Broilers}

\begin{abstract}
The objective of this work was to determine the best level of replacement of corn by wheat with 0 and $9 \%$ of germinated grains (GG) in broiler chicken diets. A mashed diet (MD) at the initial phase (0 to 21 days), crumbled diets (CD) at the growing phase (21 to 35 days) and pelleted diets (PD) at the final phase, (35 to 42 days) were used. A randomized block design with five treatments and 12 replicates with 26 birds each at the initial phase and 10 treatments and six replicates of 26 birds at the growing and finishing phases, were used. The treatments were: T1 - Corn and soybean meal based diet (DCSM), T2 and T4 - Replacement of 50\% of corn in T1 diet by wheat with 0 and $9 \%$ of germinated grains (GG), respectively; T3 and T5 - Replacement of 100\% of corn in T1 diet by wheat with 0 and $9 \%$ GG, respectively. The use of CD diets from days 21-35 and PD from 35 to 42 days of age increased the body weight (BW), weight gain (WG) and feed:gain ratio (F:G). However, feed:gain ratio was better only with CD from 21 to 35 days. The wheat with up to $9,0 \%$ GG could completely replace corn in broiler diets, when compared to DCSM. Among the wheat-soybean meal based diets, the wheat with $0 \%$ GG resulted on greater BW, WG and FC than wheat with $9 \%$ GG.
\end{abstract}

Key Words: performance, feed form, broilers, ingredients, wheat

\section{Introdução}

O trigo, no Brasil, até recentemente, não era utilizado em rações destinadas a aves e suínos, em virtude de seu preço elevado em comparação ao milho e também da disponibilidade de outros ingredientes alternativos. Segundo WARD(1995), o período entre 1992e 1994 foi atípico nos Estados Unidos, visto que os nutricionistas utilizaram trigo substituindo em até $100 \%$ o milho das dietas de suínos e aves. Contudo, segundo MARIA (1985), o grão integral normalmente só é destinado ao consumo animal, quando possui classificação inferior.
Devido aos altos preços do milho principalmente na entressafra, o trigo passou a ser alternativa ao milho na alimentação animal. De acordo com o International Wheat Council (WARD, 1995), aproximadamente 20\% do trigo produzido na safra 1993-94 foram destinados à alimentação animal, sendo a Europa, o Canadá, a Austrália e o Japão os principais consumidores. Nos Estados Unidos, aproximadamente $10 \%$ da produção de trigo, em torno de 8 milhões de toneladas, foram destinados ao consumo animal.

Nas regiões produtoras de trigo do Brasil, durante o período da colheita, é comum a ocorrência de

\footnotetext{
${ }^{1}$ Pesquisador, Embrapa Suínos e Aves, Cx. Postal 21, 89.700-000, Concórdia, SC, Brasil. E.mail: pbrum@cnpsa.embrapa.br

2 Bolsista do CNPq.

${ }^{3}$ Pesquisador, Embrapa Trigo, Cx. Postal 569, 99001-970, Passo Fundo, RS, Brasil.

${ }^{4}$ Eng ${ }^{\circ}$. Agro. MSc - Pesquisador associado, Cx. Postal 21, 89.700.000, Concórdia, SC, Brasil.
} 
chuvas, o que pode levar à alta incidência de grãos germinados, que são classificados como de 'qualidade inferior' para a indústria panificadora. Contudo, apresentam boa qualidade nutricional e grande potencial de utilização nas dietas para monogástricos e ruminantes. Por outro lado, o trigo, quando utilizado em rações peletizadas, apresenta capacidade aglutinante, melhorando a qualidade do pelete. SZUTS et al. (1988), entretanto, alertaram para o fato de que o trigo com alto teor de proteína pode causar problemas nutricionais, devido a possível imbalanço de aminoácidos na dieta. Os autores verificaram melhor desempenho de frangos alimentados com rações contendo trigo fertilizado com $50 \mathrm{~kg}$ de nitrogênio/ha, em relação às com trigo fertilizado com $150 \mathrm{~kg} \mathrm{~N} / \mathrm{kg}$, que apresentou maior nível protéico, porém menor quantidade relativa de treonina e lisina. PIENIZ et al. (1996) verificaram que a utilização de dietas à base de trigo, com até $14 \%$ de grãos germinados, e farelo de soja promoveu aumento no peso final de frangos em comparação ao uso de dieta com milho e farelo de soja. BRANTON et al. (1987), porém, observaram que dietas à base de trigo e farelo de soja determinaram peso de frangos semelhante, mas com pior conversão alimentar em contraste com dietas à base de milho e farelo de soja.

BENNETT et al. (1995) constataram que o uso de $30 \%$ de grãos de trigo inteiros nas rações finais de frangos não influiu no desempenho. Segundo ROSE (1996), as aves apresentam capacidade para utilizar grãos de trigo, uma vez que na moela podem produzir alta pressão de moagem e ação abrasiva.

O trigo é utilizado como fonte principal de energia nas dietas de aves e suínos de vários países, apesar de existir controvérsia a respeito de qual o tipo a ser utilizado, uma vez que existem vários modos para se descrever este cereal (LEESON e SUMMERS, 1997). Tradicionalmente, os cultivares de trigo foram descritos como de inverno ou primavera, de acordo com o clima e solo; algumas vezes são referenciados como branco ou vermelhos ou ainda como mole ou duro. Conforme LARBIER e LECLERK (1994), o conteúdo de energia metabolizável do trigo, expresso em base de matéria seca, é praticamente constante entre cultivares e entre anos de colheita. UDDIN et al. (1996) observaram valores de energia metabolizável verdadeira corrigida $(\mathrm{EMn})$ de $3510 \mathrm{kcal} / \mathrm{kg}$, todavia, quando os grãos foram moídos, os valores de EMn obtidos foram superiores em relação aos grãos inteiros.

ANNISON e CHOCT (1991) citam que a presença de polissacarídeos não-amiláceos na parede celular de cereais como trigo, cevada, centeio e triticale influenciam negativamente $o$ aproveitamento da energia, aumentando a retenção de água no intestino e, como consequência, a viscosidade do conteúdo intestinal. Esse efeito negativo normalmente poderá influir no desempenho dos frangos. Contudo, no estudo de PIENIZ et al. (1996), esse fenômeno não foi observado nas dietas contendo trigo.

Este experimento teve como objetivo gerar informações sobre o melhor uso do trigo com alto grau de grãos germinados em rações fareladas, trituradas e peletizadas para frangos de corte.

\section{Material e Métodos}

O experimento foi desenvolvido na EMBRAPA/ CNPSA no período de janeiro a fevereiro de 1998. Foram utilizados 1560 pintos machos de um dia de idade, de uma linhagem comercial, distribuídos em delineamento casualizado em blocos, de acordo com o peso médio inicial. As unidades experimentais foram constituídas por boxes de 26 aves. Os tratamentos foram: T1 - dieta à base de milho e farelo de soja (FS); T2 - substituição de 50\% do milho da dieta T1 por trigo com $0 \%$ de grãos germinados; T3 - dieta à base de trigo com $0 \%$ de grãos germinados e FS; T4 - substituição de $50 \%$ do milho da dieta 1 por trigo com $9 \%$ de grãos germinados; e T5 - dieta à base de trigo com $9 \%$ de grãos germinados e FS. As dietas foram isocalóricas e isoprotéicas, fornecidas à vontade, bem como a água. Foi utilizado o trigo do cultivar EMBRAPA-16, com 0 e $9 \%$ de grãos germinados, tendo peso hectolitro (ph) de 67,15 e 76,55 kg/hl, respectivamente. Na fase inicial (1-21 dias), foram usadas 12 repetições por tratamento, com rações fareladas. Nas fases de crescimento (21-35 dias) e final ( 35 a 42 dias de idade), seis repetições continuaram com ração farelada e as outras seis receberam ração triturada na fase de crescimento e peletizada na fase final. Para o cálculo das dietas, determinaram-se as energias metabolizáveis e o nível de proteína bruta dos trigos com 0 e $9 \%$ de grãos germinados, 3135 e 12,88 e $3088 \mathrm{kcal} / \mathrm{kg} 14,76 \%$ PB, respectivamente. As dietas tinham seqüencialmente 21,$0 ; 19,5 ;$ e $18,5 \%$ de proteína bruta e 3010,3100 e $3150 \mathrm{kcal} / \mathrm{kg}$ de EM nas fases inicial, de crescimento e final, respectivamente (Tabelas 1, 2 e 3). O desempenho foi avaliado por intermédio de peso corporal (PC), ganho de peso (GP), consumo de ração (CR) e conversão alimentar (CA) das aves nos períodos de 0 a 21,0 a 35 e 0 a 42 dias de idade. Nas variáveis em que o efeito de 
Tabela 1 - Composição em ingredientes e nutrientes das dietas experimentais na fase inicial Table 1 - Ingredient and nutrient composition of experimental diets used in the initial phase

Ingrediente

Tratamento

Ingredient

Milho

Corn

Farelo de soja

Soybean meal

Trigo $0,0 \%$ germinado

Wheat $0.0 \%$ germinated

Trigo $9,0 \%$ germinado

Wheat $9.0 \%$ germinated

Óleo de soja

Soybean oil

Calcário

Limestone

Fosfato bicálcico

Dicalcium phosphat

Sal

Salt

L-Lisina

L-Lysine

Dl-Metionina

Dl-Methionine

L-Treonina

L-Treonine

BHT

Premix Min. e Vitamínico ${ }^{1}$

Vit. and Min. Premix ${ }^{1}$

Promotor de crescimento

Growth promoter

Cloreto de colina

Choline chloride

Coccidicida

Coccidicide

Nutriente $^{2}$

Nutrient

Proteína bruta (\%)

Crude protein

Energia metabolizável (kcal/kg)

Metabolizable energy

Fibra bruta (\%)

Crude fiber

Cálcio (\%)

Calcium (\%)

$\mathrm{P}$ disp. (\%)

Available $P$

Metionina (\%)

Methionine

Metionina + cistina (\%)

Methionine + cystine

Lisina (\%)

Lysine

Triptofano (\%)

Tryptophan

Treonina $(\%)$

Threonine

${ }^{1} \mathrm{~kg}$ de dieta (kg of diet): $70 \mathrm{mg} \mathrm{Mn;} 50 \mathrm{mg} \mathrm{Zn;} 60 \mathrm{mg} \mathrm{Fe} ; 8 \mathrm{mg} \mathrm{Cu:} \mathrm{0,5} \mathrm{mg} \mathrm{I;} \mathrm{0,15} \mathrm{mg} \mathrm{Se;} 12.000$ UI Vit. A; $3.600 \mathrm{UI}$ Vit. D; 35 UI Vit. E; 3,00 mg Vit. K; $2,5 \mathrm{mg}$ Vit. $\mathrm{B}_{1} ; 8 \mathrm{mg}$ Vit. B2; $5 \mathrm{mg}$ Vit. $\mathrm{B}_{6} ; 0,020 \mathrm{mg}$ Vit. $\mathrm{B}_{12} ; 1,5 \mathrm{mg}$ ácido fólico (folic acid); $12 \mathrm{mg}$ ácido pantotênico (pantothenic acid); $40 \mathrm{mg}$ ácido nicotinic (nicotinic acid); e 0,2 mg de biotina (biotin).

2 Valores calculados (calculated values).

\begin{tabular}{ccccc}
$\mathrm{T} 1$ & $\mathrm{~T} 2$ & $\mathrm{~T} 3$ & $\mathrm{~T} 4$ & $\mathrm{~T} 5$ \\
\hline 56,230 & 30,800 & - & 32,100 & - \\
37,170 & 33,603 & 29,290 & 32,193 & 25,580 \\
- & 28,110 & 62,109 & - & - \\
- & - & - & 28,110 & 65,366 \\
2,450 & 3,290 & 4,330 & 3,330 & 4,570 \\
0,950 & 1,000 & 1,050 & 1,000 & 1,060 \\
2,110 & 2,100 & 2,070 & 2,110 & 2,090 \\
0,411 & 0,392 & 0,368 & 0,421 & 0,434 \\
0,021 & 0,103 & 0,200 & 0,136 & 0,288 \\
0,255 & 0,199 & 0,179 & 0,197 & 0,173 \\
- & - & 0,001 & - & 0,036 \\
0,005 & 0,005 & 0,005 & 0,005 & 0,005 \\
0,200 & 0,200 & 0,200 & 0,200 & 0,200 \\
0,005 & 0,005 & 0,005 & 0,005 & 0,005 \\
0,133 & 0,133 & 0,133 & 0,133 & 0,133 \\
0,060 & 0,060 & 0,060 & 0,060 & 0,060
\end{tabular}

\begin{tabular}{|c|c|c|c|c|}
\hline 21,00 & 21,00 & 21,00 & 21,00 & 21,00 \\
\hline 3010 & 3010 & 3010 & 3010 & 3010 \\
\hline 3,331 & 3,409 & 3,502 & 3,396 & 3,479 \\
\hline 0,950 & 0,950 & 0,950 & 0,950 & 0,950 \\
\hline 0,500 & 0,500 & 0,500 & 0,500 & 0,500 \\
\hline 0,560 & 0,520 & 0,520 & 0,520 & 0520 \\
\hline 0,940 & 0,954 & 1.020 & 0,960 & 1,039 \\
\hline 1,200 & 1,200 & 1,200 & 1,200 & 1,200 \\
\hline 0,450 & 0,434 & 0,414 & 0,422 & 0,386 \\
\hline 0,865 & 0,826 & 0,780 & 0,813 & 0,780 \\
\hline
\end{tabular}


Tabela 2 - Composição em ingredientes e nutrientes das dietas experimentais na fase de crescimento Table 2 - Ingredient and nutrient composition of experimental diets used in the growing phase Ingrediente

Ingredient Tratamento

\begin{tabular}{|c|c|c|c|c|c|}
\hline \multirow{2}{*}{ 208 } & & \multirow[b]{2}{*}{ T5 } \\
\hline & $\mathrm{T} 1$ & $\mathrm{~T} 2$ & $\mathrm{~T} 3$ & $\mathrm{~T} 4$ & \\
\hline$\overline{\text { Milho }}$ & 59,262 & 32,307 & - & 33,659 & - \\
\hline \multicolumn{6}{|l|}{ Corn } \\
\hline Farelo de soja & 33,240 & 29,510 & 25,030 & 28,010 & 21,130 \\
\hline \multicolumn{6}{|l|}{ Soybean meal } \\
\hline Trigo $0,0 \%$ germinado & - & 29,630 & 65,141 & - & - \\
\hline \multicolumn{6}{|l|}{ Wheat $0.0 \%$ germinated } \\
\hline Trigo $9,0 \%$ germinado & - & - & - & 29,630 & 68,568 \\
\hline \multicolumn{6}{|l|}{ Wheat $9.0 \%$ germinated } \\
\hline \multicolumn{6}{|l|}{ Soybean oil } \\
\hline Calcário & 0,970 & 1,010 & 1,070 & 1,010 & 1,080 \\
\hline \multicolumn{6}{|l|}{ Limestone } \\
\hline Fosfato bicálcico & 1,920 & 1,900 & 1,880 & 1,910 & 1,900 \\
\hline \multicolumn{6}{|l|}{ Dicalcium phosphate } \\
\hline Sal & 0,413 & 0,393 & 0,368 & 0,423 & 0,437 \\
\hline \multicolumn{6}{|l|}{ Salt } \\
\hline L-Lisina & 0,102 & 0,187 & 0,289 & 0,223 & 0,381 \\
\hline \multicolumn{6}{|l|}{ L-Lysine } \\
\hline Dl-Metionina & 0,218 & 0,197 & 0,176 & 0,195 & 0,171 \\
\hline \multicolumn{6}{|l|}{ Dl-Methionine } \\
\hline L-Treonina & 0,002 & 0,043 & 0,093 & 0,057 & 0,130 \\
\hline \multicolumn{6}{|l|}{ L-Threonine } \\
\hline BHT & 0,005 & 0,005 & 0,005 & 0,005 & 0,005 \\
\hline Premix Min. e Vitamínico ${ }^{1}$ & 0,190 & 0,190 & 0,190 & 0,190 & 0,190 \\
\hline \multicolumn{6}{|l|}{ Vit. and Min. Premix ${ }^{1}$} \\
\hline Promotor de crescimento & 0,005 & 0,005 & 0,005 & 0,005 & 0,005 \\
\hline \multicolumn{6}{|l|}{ Growth promoter } \\
\hline Cloreto de colina & 0,133 & 0,133 & 0,133 & 0,133 & 0,133 \\
\hline \multicolumn{6}{|l|}{ Choline chloride } \\
\hline Coccidicida & 0,060 & 0,060 & 0,060 & 0,060 & 0,060 \\
\hline Coccidicide & & & & & \\
\hline
\end{tabular}

Nutriente $^{2}$

Nutrient

\begin{tabular}{|c|c|c|c|c|c|}
\hline Proteína bruta (\%) & 19,50 & 19,50 & 19,50 & 19,50 & 19,50 \\
\hline \multicolumn{6}{|l|}{ Crude protein } \\
\hline Energia metabolizável (kcal/kg) & 3100 & 3100 & 3100 & 3100 & 3100 \\
\hline \multicolumn{6}{|l|}{ Metabolizable energy } \\
\hline Fibra bruta $(\%)$ & 3,174 & 3,254 & 3,350 & 3,240 & 3,326 \\
\hline \multicolumn{6}{|l|}{ Crude fiber } \\
\hline Cálcio (\%) & 0,900 & 0,900 & 0,900 & 0,900 & 0,900 \\
\hline \multicolumn{6}{|l|}{ Calcium (\%) } \\
\hline P disp. (\%) & 0,460 & 0,460 & 0,460 & 0,460 & 0,460 \\
\hline \multicolumn{6}{|l|}{ Avaialable $P$} \\
\hline Metionina (\%) & 0,504 & 0,500 & 0,500 & 0,500 & 0,500 \\
\hline \multicolumn{6}{|l|}{ Methionine } \\
\hline Metionina + cistina $(\%)$ & 0,860 & 0,913 & 0,982 & 0,919 & 1,001 \\
\hline \multicolumn{6}{|l|}{ Methionine + cystine } \\
\hline Lisina $(\%)$ & 1,160 & 1,160 & 1,160 & 1,160 & 1,160 \\
\hline \multicolumn{6}{|l|}{ Lysine } \\
\hline Triptofano (\%) & 0,408 & 0,391 & 0,370 & 0,379 & 0,341 \\
\hline \multicolumn{6}{|l|}{ Tryptophan } \\
\hline Treonina (\%) & 0,800 & 0,800 & 0,800 & 0,800 & 0,800 \\
\hline Threonine & & & & & \\
\hline
\end{tabular}

${ }^{1}$ Fornecendo por quilograma de dieta (Providing per kg of diet): $70 \mathrm{mg} \mathrm{Mn;} 50 \mathrm{mg} \mathrm{Zn;} 60 \mathrm{mg} \mathrm{Fe;} 8 \mathrm{mg} \mathrm{Cu:} 0,5 \mathrm{mg} \mathrm{I}$; 0,12 mg Se; 9.600 UI Vit. A; 2.880 UI Vit. D; 28 UI Vit. E; 2,40 mg Vit. K; 2 mg Vit. $B_{1} ; 6,4$ mg Vit. $B_{2} ; 4$ mg Vit. $B_{6}$ $0,016 \mathrm{mg}$ Vit. $\mathrm{B}_{12} ; 1,2 \mathrm{mg}$ ácido fólico(folic acid); $9,6 \mathrm{mg}$ ácido pantotênico (pantothenic acid); $32 \mathrm{mg}$ ácido nicotínico(niacin acid); $0,16 \mathrm{mg}$ biotina(biotin).

2 Valores calculados (calculated values). 
172 Rev. bras. zootec.

Tabela 3 - Composição em ingredientes e nutrientes das dietas experimentais na fase final Table 3 - Ingredient and nutrient composition of experimental diets used in the final phase

Ingrediente Tratamento

Ingredient

Treatment

\begin{tabular}{|c|c|c|c|c|c|}
\hline & $\mathrm{T} 1$ & $\mathrm{~T} 2$ & $\mathrm{~T} 3$ & $\mathrm{~T} 4$ & $\mathrm{~T} 5$ \\
\hline Milho & 61,905 & 33,761 & - & 35,171 & - \\
\hline Corn & & & & & \\
\hline Farelo de soja & 30,510 & 26,610 & 21,930 & 25,040 & 17,860 \\
\hline Soybean meal & & & & & \\
\hline Trigo $0,0 \%$ germinado & - & 30,950 & 68,049 & - & - \\
\hline Wheat $0.0 \%$ germinated & & & & & \\
\hline Trigo $9,0 \%$ germinado & - & - & - & 30,950 & 71,629 \\
\hline Wheat $9.0 \%$ germinated & & & & & \\
\hline $\begin{array}{l}\text { Óleo de soja } \\
\text { Sovbean oil }\end{array}$ & 3,820 & 4,800 & 5,990 & 4,860 & 6,250 \\
\hline Calcário & 0,940 & 0,990 & 1,050 & 0,990 & 1,060 \\
\hline Limestone & & & & & \\
\hline $\begin{array}{l}\text { Fosfato bicálcico } \\
\text { Dicalcium phosphate }\end{array}$ & 1,770 & 1,750 & 1,730 & 1,770 & 1,750 \\
\hline Sal & 0,414 & 0,393 & 0,368 & 0,425 & 0,439 \\
\hline $\begin{array}{l}\text { Salt } \\
\text { L-Lisina }\end{array}$ & 0,116 & 0,205 & 0,311 & 0,241 & 0,407 \\
\hline L-Lysine & & & & & \\
\hline $\begin{array}{l}\text { Dl-Metionina } \\
\text { Dl-Methionine }\end{array}$ & 0,186 & 0,158 & 0,137 & 0,156 & 0,131 \\
\hline $\begin{array}{l}\text { L-Treonina } \\
\text { L-Treonine }\end{array}$ & 0,047 & 0,091 & 0,143 & 0,105 & 0,182 \\
\hline BHT & 0,005 & 0,005 & 0,005 & 0,005 & 0,005 \\
\hline $\begin{array}{l}\text { Premix Min. e Vitamínico }{ }^{1} \\
\text { Vit. and Min. Premix }\end{array}$ & 0,170 & 0,170 & 0,170 & 0,170 & 0,170 \\
\hline $\begin{array}{l}\text { Cloreto de colina } \\
\text { Choline chloride }\end{array}$ & 0,117 & 0,117 & 0,117 & 0,117 & 0,117 \\
\hline
\end{tabular}

Nutriente $^{2}$

Nutrient

\begin{tabular}{|c|c|c|c|c|c|}
\hline Proteína bruta (\%) & 18,50 & 18,50 & 18,50 & 18,50 & 18,50 \\
\hline \multicolumn{6}{|l|}{ Crude protein } \\
\hline $\mathrm{EM}(M E) \mathrm{kcal} / \mathrm{kg}$ & 3150 & 3150 & 3150 & 3150 & 3150 \\
\hline Fibra bruta $(\%)$ & 3,076 & 3,160 & 3,260 & 3,145 & 3,235 \\
\hline \multicolumn{6}{|l|}{ Crude fiber } \\
\hline Cálcio (\%) & 0,850 & 0,850 & 0,850 & 0,850 & 0,850 \\
\hline $\begin{array}{l}\text { Calcium } \\
\text { P disponível (\%) }\end{array}$ & 0,430 & 0,430 & 0,430 & 0,430 & 0,430 \\
\hline \multicolumn{5}{|l|}{ Available $P$} & 0,450 \\
\hline \multicolumn{6}{|l|}{ Methionine } \\
\hline \multicolumn{6}{|l|}{ Methionine + cystine } \\
\hline $\begin{array}{l}\text { Lisina }(\%) \\
\text { Lysine }\end{array}$ & 1,100 & 1,100 & 1,100 & 1,100 & 1,100 \\
\hline $\begin{array}{l}\text { Triptofano }(\%) \\
\text { Tryptophan }\end{array}$ & 0,379 & 0,361 & 0,340 & 0,349 & 0,309 \\
\hline $\begin{array}{l}\text { Treonina }(\%) \\
\text { Threonine }\end{array}$ & 0,800 & 0,800 & 0,800 & 0,800 & 0,800 \\
\hline
\end{tabular}

$1 \mathrm{~kg}$ de dieta (kg of diet): $70 \mathrm{mg} \mathrm{Mn} ; 50 \mathrm{mg} \mathrm{Zn;60} \mathrm{mg} \mathrm{Fe;} 8 \mathrm{mg} \mathrm{Cu:} 0,5 \mathrm{mg} \mathrm{l} ; 0,09 \mathrm{mg}$ Se; 7.200 UI Vit. A; $2.160 \mathrm{UI}$ Vit. D; 21 UI Vit. E; $1,8 \mathrm{mg}$ Vit. K; $1,5 \mathrm{mg}$ Vit. $B_{1} ; 4,8 \mathrm{mg}$ Vit. $\mathrm{B}_{2} ; 3 \mathrm{mg}$ Vit. $\mathrm{B}_{6} ; 0,012 \mathrm{mg}$ Vit. $\mathrm{B}_{1} ; 0,9 \mathrm{mg}$ ácido fólico (folic acid); $7,2 \mathrm{mg}$ ácido pantotênico (pantothenic acid); $24 \mathrm{mg}$ ácido nicotínico (nicotinic acid); $0,12 \mathrm{mg}$ biotina (biotin).

2 Valores calculados (calculated values). 
tratamento foi significativo, por meio da análise de variância $(\mathrm{P}<0,05)$, foram feitos contrastes para determinar o efeito da substituição do milho pelo trigo (T1 versus T2,T3,T4,T5), o nível de substituição do milho pelo trigo, excetuando-se o T1 (T2,T4 versus T3,T5), o grau de germinação (T2,T3 versus T4,T5) e a interação nível versus germinação (T2,T5 versus $\mathrm{T} 3, \mathrm{~T} 4)$.

\section{Resultados e Discussão}

Considerando-se a interação entre os fatores níveis de substituição, a porcentagem de grãos germinados e as formas físicas das rações, não se observou efeito significativo.

Comparando-se os tratamentos (Tabela 4) nos três períodos estudados, verificaram-se efeitos significativos em algumas variáveis. No período de 1 a
21 dias de idade, os frangos alimentados com dietas contendo trigo com $0 \%$ de grãos germinados, substituindo 50 ou $100 \%$ do milho, apresentaram maior PC, GP e CR em relação aos animais que receberam a dieta à base de milho e farelo de soja (Testemunha), porém a CA não foi influenciada pelos tratamentos. Contudo, os tratamentos com trigo com $9 \%$ de grãos germinados, substituindo 50 ou $100 \%$ do milho, não diferiram significativamente dos demais. PIENIZ et al. (1996) também verificaram melhor desempenho de frangos de corte de 1 a 21 dias de idade, ao substituírem o milho pelo trigo nas dietas.

Considerando-se o período de 1 a 35 dias de idade dos frangos, constatou-se que a utilização do trigo com $0 \%$ de grãos germinados na dieta, substituindo $50 \%$ do milho, melhorou o PC e o GP dos frangos em comparação à dieta testemunha, porém não houve efeito no CR ou na CA. Por outro lado, a dieta com

Tabela 4 - Efeito das dietas com diferentes níveis de substituição do milho pelos trigos com 0 e $9 \%$ de grãos germinados no desempenho de frangos de corte no período de 0 a 42 dias de idade

Table 4 - Effect of diets with different levels of replacement of corn by wheat with 0 or $9 \%$ of germinated grains on the performance of broilers from day 1 to 42 of age

\begin{tabular}{|c|c|c|c|c|c|c|}
\hline \multirow{3}{*}{$\begin{array}{l}\text { Variável }^{1} \\
\text { Variable }^{2}\end{array}$} & \multirow{3}{*}{$\begin{array}{l}\text { Milho } \\
\text { Corn } \\
\text { Far. Soja } \\
\text { Soybeam } \\
\text { meal }^{2}\end{array}$} & \multicolumn{4}{|c|}{$\begin{array}{l}\text { Trigo } \\
\text { Wheat }\end{array}$} & \multirow{3}{*}{$\mathrm{EP}^{4}$} \\
\hline & & \multicolumn{2}{|c|}{$0 \% 3$} & \multicolumn{2}{|c|}{$9 \%^{3}$} & \\
\hline & & $50 \%^{5}$ & $100 \%^{5}$ & $50 \%{ }^{5}$ & $100 \% 5$ & \\
\hline \multirow[t]{2}{*}{ PI (g) } & 46,91 & 47,19 & 47,05 & 46,95 & 46,97 & 0,13 \\
\hline & \multicolumn{5}{|c|}{$\begin{array}{l}0-21 \text { dias } \\
0-21 \text { days }\end{array}$} & \\
\hline $\begin{array}{l}\text { PC }(g) \\
\text { GP }(g) \\
\text { CR }(g) \\
\text { CA }\end{array}$ & $\begin{array}{c}752 b^{6} \\
705 b \\
1044 b \\
1,48 \\
\end{array}$ & $\begin{array}{c}778 \mathrm{a} \\
731 \mathrm{a} \\
1105 \mathrm{a} \\
1,51 \\
\end{array}$ & $\begin{array}{c}777 \mathrm{a} \\
730 \mathrm{a} \\
1087 \mathrm{a} \\
1,49 \\
\end{array}$ & $\begin{array}{c}769 \mathrm{ab} \\
722 \mathrm{ab} \\
1075 \mathrm{ab} \\
1,49\end{array}$ & $\begin{array}{c}768 \mathrm{ab} \\
721 \mathrm{ab} \\
1090 \mathrm{a} \\
1,51 \\
\end{array}$ & $\begin{array}{c}6,05 \\
6,04 \\
11,34 \\
0,01\end{array}$ \\
\hline CA & \multicolumn{5}{|c|}{$\begin{array}{l}0-35 \text { dias } \\
0-35 \text { days }\end{array}$} & \\
\hline $\begin{array}{l}\mathrm{PC}(\mathrm{g}) \\
\mathrm{GP}(\mathrm{g}) \\
\mathrm{CR}(\mathrm{g}) \\
\mathrm{CA} \\
\end{array}$ & $\begin{array}{c}1870 b c \\
1823 b c \\
2999 \\
1,65 \\
\end{array}$ & $\begin{array}{c}1914 \mathrm{a} \\
1866 \mathrm{a} \\
3063 \\
1,64 \\
\end{array}$ & $\begin{array}{c}1893 \mathrm{ab} \\
1846 \mathrm{ab} \\
3037 \\
1,65 \\
\end{array}$ & $\begin{array}{c}1894 \mathrm{ab} \\
1847 \mathrm{ab} \\
3024 \\
1,64 \\
\end{array}$ & $\begin{array}{c}1851 \mathrm{c} \\
1804 \mathrm{c} \\
3002 \\
1,66 \\
\end{array}$ & $\begin{array}{c}12,37 \\
12,34 \\
22,12 \\
0,01 \\
\end{array}$ \\
\hline & \multicolumn{5}{|c|}{$\begin{array}{l}0-42 \text { dias } \\
0-42 \text { days }\end{array}$} & \\
\hline $\mathrm{PC}(\mathrm{g})$ & $2370 c$ & $2451 a$ & $2429 \mathrm{ab}$ & $2408 \mathrm{abc}$ & $2396 b c$ & 16,18 \\
\hline $\mathrm{GP}(\mathrm{g})$ & $2323 c$ & $2404 a$ & $2382 \mathrm{ab}$ & 2361abc & $2349 b c$ & 16,18 \\
\hline CR $(\mathrm{g})$ & 4207 & 4307 & 4272 & 4237 & 4220 & 29,35 \\
\hline $\mathrm{CA}$ & 1,81 & 1,79 & 1,79 & 1,80 & 1,80 & 0,01 \\
\hline
\end{tabular}


174 Rev. bras. zootec.

trigo com $0 \%$ de grãos germinados substituindo $100 \%$ do milho e a dieta com $9 \%$ de grãos germinados substituindo $50 \%$ do milho não diferiram significativamente com relação às variáveis estudadas, tanto em contraste com as dietas com $0 \%$ de grãos germinados substituindo em $50 \%$ o milho como com a testemunha. Nesse período, a dieta que determinou menor PC e GP foi aquela contendo trigo com $9 \%$ de grãos germinados substituindo $100 \%$ do milho, comparável somente à testemunha, contudo, não se constataram efeitos no $\mathrm{CR}$ ou na $\mathrm{CA}$ em relação às demais dietas.

No período de 1 a 42 dias de idade, o efeito entre os tratamentos foi similar ao período de 1 a 35 dias, não havendo diferenças significativas quanto ao $\mathrm{CR}$ ou à CA. Considerando-se o PC e GP dos frangos, verificou-se que as dietas contendo trigo com $0 \%$ de grãos germinados, substituindo em até $100 \%$ o milho, foram melhores que a testemunha. Contudo, não diferiram da dieta contendo trigo com $9 \%$ de grãos germinados, substituindo em 50\% o milho, que foi semelhante à dieta com trigo com $9 \%$ de grãos germinados substituindo em $100 \%$ o milho. As dietas contendo trigo com $9 \%$ de grãos germinados, com até $100 \%$ de substituição do milho, foram semelhantes em PC e GP em comparação à testemunha.

Os resultados do período total (1 a 42 dias de idade) deste experimento mostraram que, substituindo o milho em $50 \%$ por trigo com $9 \%$ de grãos

Tabela 5 - Efeito do nível de substituição ( $50 \%$ e dieta sem milho) do milho pelo trigo e da porcentagem de grãos germinados (0 e $9 \%$ ) sobre peso corporal, ganho de peso, consumo de ração e conversão alimentar de frangos de corte, nos períodos de 1 a 21, 1 a 35 e 1 a 42 dias de idade

Table 5 - Effect of replacement level (50\% and diet without corn) of corn by wheat and germination level $(0$ and $9 \%)$ on body weight, weight gain, feed intake and feed:gain ratio of broilers from 1 to 21, 1 to 35 and 1 to 42 days of age

\begin{tabular}{|c|c|c|c|c|}
\hline \multirow[t]{2}{*}{$\begin{array}{l}\text { Variáveis } \\
\text { Variables }\end{array}$} & \multicolumn{2}{|c|}{$\begin{array}{c}\text { Substituição (\%) } \\
\text { Replacement }\end{array}$} & \multicolumn{2}{|c|}{$\begin{array}{l}\text { Grão germinado (\%) } \\
\text { Germinated grain }\end{array}$} \\
\hline & 50 & $100^{1}$ & 0 & 9 \\
\hline \multirow{2}{*}{\multicolumn{5}{|c|}{$\begin{array}{l}1 \text { a } 21 \text { dias de idade } \\
1 \text { to } 21 \text { days of age }\end{array}$}} \\
\hline & & & & \\
\hline Peso corporal (g) & 774 & 773 & 778 & 769 \\
\hline Bodyweight & & & & \\
\hline Ganho de peso (g) & 727 & 726 & 731 & 722 \\
\hline Weigth gain & & & & \\
\hline Consumo de ração $(\mathrm{g})$ & 1090 & 1089 & 1096 & 1083 \\
\hline Feedintake & & & & \\
\hline $\begin{array}{l}\text { Conversão alimentar } \\
\text { Feed:gain ratio }\end{array}$ & 1,50 & 1,50 & 1,50 & 1,50 \\
\hline \multicolumn{5}{|l|}{$\begin{array}{l}1 \text { a } 35 \text { dias de idade } \\
1 \text { to } 35 \text { days of age }\end{array}$} \\
\hline $\begin{array}{l}\text { Peso corporal }(\mathrm{g})^{2} \\
\text { Bodyweight }\end{array}$ & $1904^{\mathrm{a}}$ & $1872^{b}$ & $1904^{\mathrm{a}}$ & $1873^{\mathrm{b}}$ \\
\hline $\begin{array}{l}\text { Ganho de peso }(\mathrm{g})^{2} \\
\text { Weigth gain }\end{array}$ & $1857^{\mathrm{a}}$ & $1825^{\mathrm{b}}$ & $1856^{\mathrm{a}}$ & $1826^{\mathrm{b}}$ \\
\hline $\begin{array}{l}\text { Consumo de ração }(\mathrm{g}) \\
\text { Feed intake }\end{array}$ & 3044 & 3020 & 3050 & 3013 \\
\hline $\begin{array}{l}\text { Conversão alimentar } \\
\text { Feed:gain ratio }\end{array}$ & 1,65 & 1,66 & 1,65 & 1,65 \\
\hline \multicolumn{5}{|l|}{$\begin{array}{l}1 \text { a } 42 \text { dias de idade } \\
1 \text { to } 42 \text { days of age }\end{array}$} \\
\hline $\begin{array}{l}\text { Peso corporal }(\mathrm{g})^{2} \\
\text { Bodyweight }\end{array}$ & 2430 & 2413 & $2440^{\mathrm{a}}$ & $2402^{b}$ \\
\hline $\begin{array}{l}\text { Ganho de peso }(\mathrm{g})^{2} \\
\text { Weigth gain }\end{array}$ & 2383 & 2366 & $2393^{\mathrm{a}}$ & $2355^{\mathrm{b}}$ \\
\hline $\begin{array}{l}\text { Consumo de ração }(\mathrm{g})^{2} \\
\text { Feed intake }\end{array}$ & 4272 & 4246 & $4290^{\mathrm{a}}$ & $4229^{b}$ \\
\hline $\begin{array}{l}\text { Conversão alimentar } \\
\text { Feed:gain ratio }\end{array}$ & 1,80 & 1,80 & 1,79 & 1,80 \\
\hline
\end{tabular}

\footnotetext{
1 Dietas à base de trigo e farelo de soja, sem milho (Diets based on wheat and soybean meal, without corn).

2 Médias, na linha, seguidas de letras deferentes são diferentes $(P<0,05)$ (Means within a row followed by different letters are different $[P<.05])$.
} 
germinados, como os resultados de REDDY et al. (1979) e BRANTON et al. (1987), ou substituindo totalmente o milho, como PIENIZ et al. (1996), o desempenho dos frangos de corte até os 42 dias de idade não foi influenciado, ao se fornecer dieta à base de milho e farelo de soja. Contudo, considerando-se a utilização de dietas contendo trigo com $0 \%$ de grãos germinados, substituindo em até $100 \%$ o milho, verificou-se maior PC e GP, quando comparados aos determinados pela dieta à base de milho e farelo de soja.

Muitos autores, como ANNISON e CHOCT (1991), citam que a presença de polissacarídeos nãoamiláceos da parede celular de cereais como o trigo, cevada, centeio e triticale influenciam o aproveitamento da energia, aumentando a retenção de água no intestino e, como conseqüência, a viscosidade do fluído intestinal. Este efeito negativo normalmente poderá influir no desempenho dos frangos, contudo, no presente estudo e no de PIENIZ et al. (1996), esse fenômeno não foi observado nas dietas contendo trigo. Talvez existam diferenças entre os cultivares utilizados, quanto ao teor de polissacarídeos nãoamiláceos, o que explicaria o efeito positivo da utili- zação do trigo em relação à substituição do milho.

Entre os contrastes estudados, não se verificou interação significativa entre os níveis de substituição do milho pelo trigo e níveis de grãos germinados (T2,T5 versus T3,T4), para qualquer das variáveis estudadas, em nenhum dos períodos estudados. $\mathrm{Na}$ Tabela 5, são apresentados os contrastes entre os tratamentos contendo trigo (50 e $100 \%$ de substituição) e entre os tratamentos contendo diferentes níveis de grãos germinados (0 e 9\%). Verificou-se que não houve efeito significativo em PC, GP, CR ou CA no período de 0 a 21 dias de idade. No período de 1 a 35 dias de idade, observou-se que a substituição de $50 \%$ do milho pelo trigo determinou maiores PC e GP em relação a $100 \%$ de substituição e a utilização de trigo com $0 \%$ de grãos germinados também determinou maiores PC e GP em contraste ao trigo com $9 \%$ de grãos germinados.

No período total (0 a 42 dias de idade), somente houve efeito de porcentagem de grãos germinados, sendo que o uso de trigo com $0 \%$, nas dietas, aumentou significativamente o PC, GP e CR em relação ao trigo com $9 \%$ de grãos germinados. Isso demonstrou

Tabela 6 - Efeito da forma física das rações para ganho de peso, consumo de ração e conversão alimentar dos frangos de corte nos períodos de 21 a 35 e 35 a 42 dias de idade

Table 6 - Effect of physical form of diets on weight gain, feed intake and feed:gain ratio of broilers from 21 to 35 and 35 to 42 days of age

\begin{tabular}{|c|c|c|}
\hline \multirow[t]{2}{*}{$\begin{array}{l}\text { Variável } \\
\text { Variable }\end{array}$} & \multicolumn{2}{|c|}{$\begin{array}{c}\text { Forma física das rações } \\
\text { Physical form of diets }\end{array}$} \\
\hline & $\begin{array}{c}\text { Farelada } \\
\text { Mashed meals }\end{array}$ & $\begin{array}{c}\text { Triturada } \\
\text { Crumbled meals }\end{array}$ \\
\hline $\begin{array}{l}\text { Ganho de peso 21-35 } \\
\text { Weigth gain }\end{array}$ & $1064 b^{1}$ & $1167 \mathrm{a}$ \\
\hline $\begin{array}{l}\text { Consumo de ração 21-35 } \\
\text { Feed intake }\end{array}$ & $1908 b$ & $1983 a$ \\
\hline $\begin{array}{l}\text { Conversão alimentar 21-35 } \\
\text { Feed:gain ratio }\end{array}$ & $1,79 \mathrm{a}$ & $1,70 \mathrm{~b}$ \\
\hline $\begin{array}{l}\text { Peso corporal } 35 \\
\text { Body weight }\end{array}$ & $1834 b$ & $1934 a$ \\
\hline $\begin{array}{l}\text { Variável } \\
\text { Variable }\end{array}$ & $\begin{array}{c}\text { Farelada } \\
\text { Mashed meals }\end{array}$ & $\begin{array}{l}\text { Peletizada } \\
\text { Pelleted }\end{array}$ \\
\hline $\begin{array}{l}\text { Ganho de peso } 35-42 \\
\text { Weigth gain }\end{array}$ & $515 b$ & $538 \mathrm{a}$ \\
\hline $\begin{array}{l}\text { Consumo de ração } 35-42 \\
\text { Feed intake }\end{array}$ & $1176 b$ & $1271 \mathrm{a}$ \\
\hline $\begin{array}{l}\text { Conversão alimentar } 35-42 \\
\text { Feed:gain ratio }\end{array}$ & 2,30 & 2,37 \\
\hline $\begin{array}{l}\text { Peso corporal } 42 \\
\text { Body weight }\end{array}$ & $2349 b$ & $2473 a$ \\
\hline
\end{tabular}

Medias, na linha, seguidas de letras deferentes são diferentes $(P<0,05)$.

Means within a row followed by different letters are different $(P<.05)$. 
que o desempenho dos frangos não foi influenciado, ao se substituir o milho por trigo parcial ou totalmente. Similarmente, SHARMA e SHARMA (1993) não verificaram efeitos significativos no peso corporal ou na conversão alimentar, quando compararam a substituição 54\% do milho por trigo em dietas para frangos de corte até oito semanas de idade, ou quando incluíram até $63 \%$ de trigo em dietas para galos adultos durante 12 semanas. PIENIZ et al. (1996) relataram resultados semelhantes, quando utilizaram trigos com 2 e 14\% de grãos germinados em dietas para frangos de corte. Porém, no presente experimento houve efeito da utilização de trigo com diferentes porcentagens de grãos germinados nas dietas.

Constam da Tabela 6 os contrastes quanto às formas físicas das rações, a partir da idade de 21 dias de idade dos frangos, uma vez que no período de 1 a 21 dias de idade todos os frangos foram criados com ração na forma farelada. Os resultados mostraram que, no período de 21 a 35 dias de idade, a utilização de rações trituradas melhorou o GP, a CA e o PC aos 35 dias. O CR foi significativamente maior nas aves que receberam ração triturada que nas aves alimentadas com rações fareladas. No período de 35 a 42 dias de idade, os frangos que receberam rações peletizadas apresentaram maior GP, CR e PC aos 42 dias, porém CA semelhante, em relação aos frangos que consumiram rações fareladas. Estes resultados mostraram que o desempenho de frangos de corte é melhorado, quando se utilizam rações trituradas na fase de crescimento e peletizadas na fase final em comparação com rações fareladas. Estes resultados concordam com os de KLEIN (1996), que verificou melhor desempenho dos frangos alimentados com dietas peletizadas em contraste com dietas fareladas.

\section{Conclusões}

O trigo com até $9 \%$ dos grãos germinados pode substituir totalmente o milho em dietas para frangos de corte, quando comparadas à dieta à base de milho e farelo de soja.

Entre dietas à base de trigo e farelo de soja, o trigo com $0 \%$ de grãos germinados determinou maior GP, PC e CR que o trigo com $9 \%$ de grãos germinados.

A utilização de rações trituradas, no período de 21 a 35 dias, e peletizadas, no período de 35 a 42 dias de idade, proporcionou melhor desempenho dos frangos de corte em relação às fareladas. Todavia, a conversão alimentar não foi influenciada no período de 35 a 42 dias de idade dos frangos.

\section{Referências Bibliográficas}

ANNISON, G., CHOCT, M.. 1991. Anti-nutritive activities of cereal non starch polysaccharides in broiler diets and strategies minimizing theirs effects. World's Poult. Sci. J., 47:232-242.

BENNETT, C. D., CLASEEN, H. L., RIDDELL, C. 1995. Live performance and health of broiler chickens fed diets diluted with whole or crumbled wheat. Can. J. Anim. Sci., 75:611-614.

BRANTON, S. L., REECE, F. N., HAGLER JR., W. M.. 1987. Nutritive value of new cultivars of triticale and wheat for broiler chick diets. Poult. Sci., 66:1326-1330.

MARIA, B, de. 1985. Feed use of wheat. Feed Management, 36:32-32.

KLEIN. C.H. Efeito da forma física e do nível de energia da ração sobre o desempenho, a composição de carcaça e a eficiência de utilização da energia metabolizável consumida por frangos de corte. Porto Alegre, RS: UFRGS, 1996. 97p. Dissertação (Mestrado em Zootecnia) - Universidade Federal do Rio Grande do Sul, 1996.

LARBIER, M., LECLERK, B. 1994. Nutrition and feeding of poultry. Nottingham: Nottingham University Press. 305p.

LEESSON, S., SUMMERS, J. D. 1997. Ingredient evaluation and diet formulation. In: LEESON, S., SUMMERS, J.D. (Eds.) Commercial poultry nutrition. 2.ed. Ghelph: University Books. p.10-11.

PIENIZ, L.C., ZANOTTO, D. L., GUIDONI, A. L. et al. Trigo em substituição ao milho em rações para frangos de corte. In: REUNIÃO ANUAL DA SOCIEDADE BRASILEIRA DE ZOOTECNIA, 33, 1996, Fortaleza, CE. Anais... Fortaleza: SBZ, 1996. p.94-95.

REDDY, N.V., RAO, D.R., SUNKI, G.R. 1979. Comparison of maize, wheat and triticale in broiler diets. Poul. Sci., 20:357362.

ROSE, S.P. 1996. The use of whole wheat in poultry diets. World's Poult. Sci. J., 51(1):59-60.

SHARMA, P.K., SHARMA, R.K. 1993. Effect of replacement of maize with wheat on growth performance of broilers and cockerels. Indian J. Anim. Prod. Manag., 9:127-129.

SZUTS, C., VINCZE, L., KOVACS, G. et al. 1988. Effect of soil fertility on the amino acids and nutritional value of wheat grain. Acta Vet. Hung., 36:137-142.

UDDIN, S.M., ROSE, S.P., HISTCOCK, T.A. et al. 1996. A comparison of the energy availability for chickens of ground and whole grain samples of two wheat varieties. Br. Poult. Sci., 37:347-357.

WARD, N.E. 1995. With dietary modifications, wheat can be used for poultry. Feedstuffs, 67(33):14-15.

Recebido em: 07/12/98

Aceito em: 21/05/99 